\title{
A NEW SEISMIC RESPONSE CONTROL TECHNIQUE FOR BUILDINGS USING BLOCK AND TACKLE
}

\author{
Taiki SAITO ${ }^{1}$ \\ ${ }^{1}$ Department of Architecture and Civil Engineering, Toyohashi University of Technology, Toyohashi, Japan
}

Received: 12/08/2019 Accepted: 12/08/2019

\begin{abstract}
The author proposed a new seismic response control system using a block and tackle (hereinafter, referred to as a dynamic pulley damper system) developed especially for the high-rise buildings. The proposed system has a configuration where a damper is installed on the track of the cable-stayed wire, amplifying the amount of movement of the wire by using a movable pulley that increases the damping effect to reduce the vibration of a building. we apply this system to connect the core structure (parking tower) and the surrounding frame (housing part) of a high-rise building. This system aims to reduce the earthquake response of the building by the force of the damper attached to the core structure. To verify the effectiveness of this response control system, two types of shaking table tests were conducted; one is the large-scale shaking table test using a magnetic damper, an-other one is the small-scale shaking table test using a steel damper. The mathematical model of the dynamic pulley damper system to implement the frame analysis was developed and the results of simulation analysis are compared with the experiments.
\end{abstract}

Keywords: Response control, High-rise building, Block and tackle, Earthquake, Damper

\section{INTRODUCTION}

At the 2011 Great East Japan Earthquake, the highrise buildings in Tokyo, Nagoya and Osaka swayed significantly and caused damage to non-structural elements such as deformation of fire protection walls and dropping of ceiling panels. To reduce building vibration during an earthquake, it has become popular in Japan to install vibration control devices such as oil dampers in high-rise buildings. Those dampers are generally installed inside the building frame to work against the shear deformation of the frame. However, since the laterale-formation of the high-rise building contains the large ratio of flexural component in the up-per stories, the dampers cannot work effectively to reduce the response of the high-rise buildings. To overcome this problem, the various techniques have been developed including the application of TMD (Tuned Mass Damper) system [1].

The author proposed a new seismic response control system using a block and tackle (hereinafter, referred to as a dynamic pulley damper system) developed especially for the high-rise buildings $[2,3]$.
The proposed system has a configuration where a damper is installed on the track of the cable-stayed wire, amplifying the amount of movement of the wire by using a movable pulley that increases the damping effect to reduce the vibration of a building. The principle of this mechanism is shown in Figure 1. The wire is stretched to reciprocate between the pulley groups $A$ and $B$, and one end of the wire is connected to the damper. Wires and pulleys are arranged on the other side of the damper under the same condition. When the building moves during an earthquake, the amount of displacement $D$ between $A$ and $B$ is enlarged by the number $\mathrm{n}$ of wires between them, and the damper can move by $n \times D$.

At the same time, the damper force is expanded $n$ times and acts on the building. The proposed system has a configuration where a damper is installed on the track of the cable-stayed wire, amplifying the amount of movement of the wire by using a movable pulley that increases the damping effect to reduce the vibration of a building. Since the wire can be stretched across distant parts of a building, this system is able to exert an effect on a large relative displacement.

Corresponding author:

tsaito@ace.tut.ac.jp 


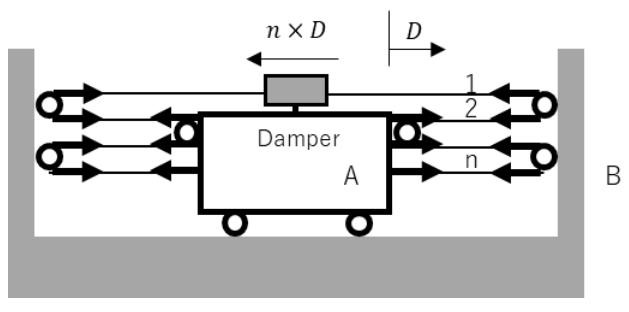

Figure 1. Mechanism of dynamic pully damper system

A series of experimental studies on this system have been conducted to confirm the damping effect and evaluate the effect of the wire elongation and the friction with the pulley $[4,5]$. The features of this vibration control structure system are summarized as follows:

(1) It enables to increase the damping effect greatly by amplifying the movement of the wire with respect to the deformation of the building.

(2) Even the damper with small capacity can be used if the stroke of damper is large.

(3) Since the wire can be stretched between different spans or different stories, various arrangements are possible to install the system.

In this research, as shown in Figure 2, we consider applying the dynamic pulley damper system to a highrise condominium consisting of a surrounding frame (housing part) and a core part (parking tower). The surrounding frame and the core part are connected by a wire through pulleys and a damper device is installed at the top of the core. The movable pulleys amplify the relative displacement of two structures, and the damper moves largely to dissipate energy to reduce the vibration of the surrounding frame.

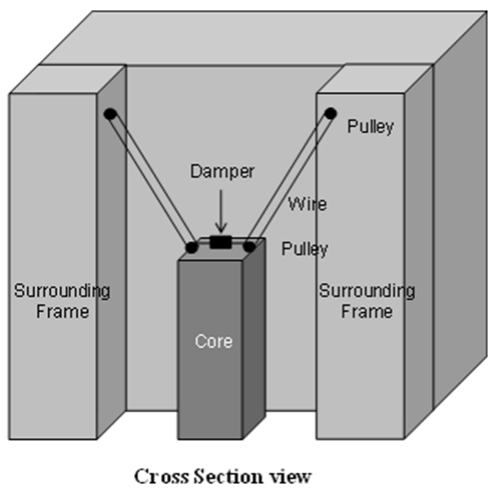

Figure 2. Arrangement of a movable pulley damper system to a highrise building with a core structure

\section{CONSTITUTIVE FORMULA}

A force-deformation relationship of the dynamic pulley damper system considering elongation of the wire is derived below. It is assumed that stretching due to temperature change and deflection due to the mass of the wire are ignored in the derivation.
The following conditions are established when implementing a dynamic pulley damper system into a frame. As shown in Figure 3, the wire is stretched between the pulleys installed at any four points in the frame, and the wire of the diagonal part is reciprocated between the pulleys to increase the movement of the damper installed at the top or bottom of the system. The wire and the damper are arranged in the same plane in a global coordinate system, and the upper and lower sides of the wire are parallel to the horizontal plane as shown in Figure 4.

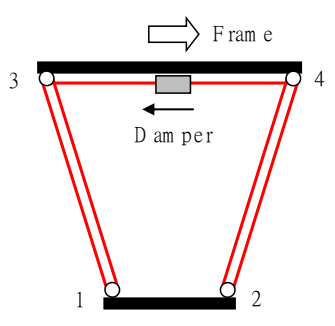

(a) D yn am ic pully dam per system

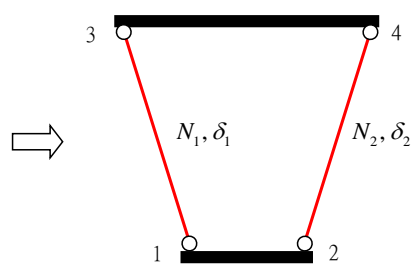

(b) Equivalen $t$ truss m odel
Figure 3. Basic configuration of the system
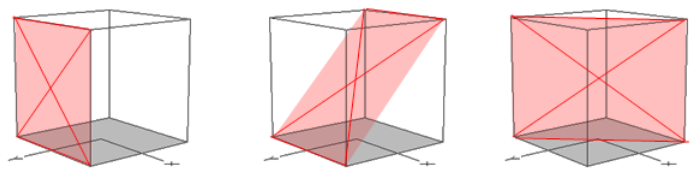

Figure 4. Arrangement of the system in a global coordinate

For the left side of the system as shown in Figure 5, the force-deformation relationships of the wires in the oblique and horizontal parts are expressed as follows.
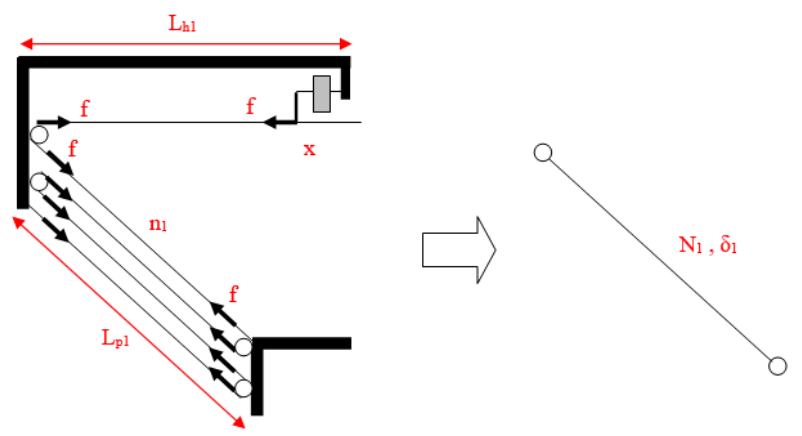

Figure 5. Left side of the pulley damper system

$$
\begin{aligned}
& f=K_{p 1}\left(d_{p 1} / n_{1}\right), \quad K_{p 1}=E A / L_{p 1} \\
& f=K_{h 1} d_{h 1}, \quad K_{h 1}=E A / L_{h 1}
\end{aligned}
$$

where, $f$ is the tension force of the wire, $d_{p 1}, L_{p 1}$ are the wire elongation and the pulley distance of the oblique part, $n_{1}$ is the number of reciprocations of the wire in the oblique part, $d_{h 1}, L_{h 1}$ are the wire elongation and the pulley distant of the horizontal part 
between the pulley and the damper, and $E, A$ are the Young's modulus and the cross section area of the wire. The force and deformation of the equivalent truss are

$$
N_{1}=n_{1} f, \quad \delta_{1}=\left(d_{p 1}+d_{h 1}+x\right) / n_{1}
$$

where, $x$ is the deformation of the damper, $\delta_{1}, N_{1}$ are the axial deformation and force of the truss.

Similarly, for the right side of the system as shown in Figure 6, the force-deformation relationships of the wires in the oblique and horizontal parts are expressed as follows.
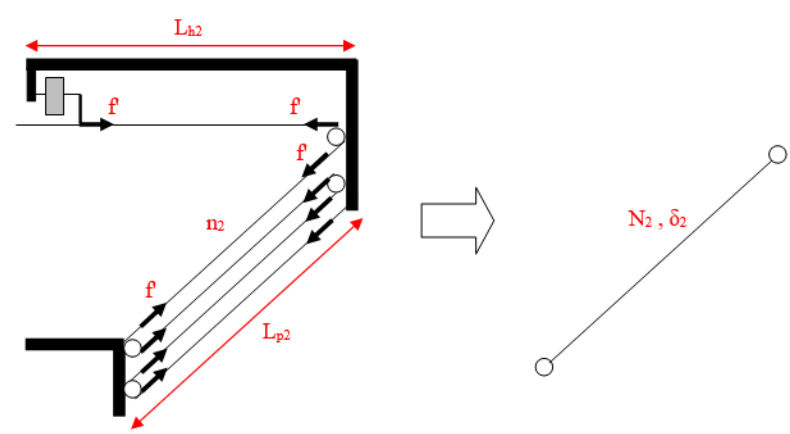

Figure 6. Right side of the pulley damper system

$$
\begin{aligned}
& f^{\prime}=K_{p 2}\left(d_{p 2} / n_{2}\right), \quad K_{p 2}=E A / L_{p 2} \\
& f^{\prime}=K_{h 2} d_{h 2}, \quad K_{h 2}=E A / L_{h 2}
\end{aligned}
$$

The force and deformation of the equivalent truss are

$$
N_{2}=n_{2} f^{\prime}, \quad \delta_{2}=\left(d_{p 2}+d_{h 2}-x\right) / n_{2}
$$

For the whole system as shown in Figure 7, the tension forces of the left and right wires act on the damper and the damper force is evaluated as

$$
Q(x, \dot{x})=f-f^{\prime}
$$

If one of the left and right wires stretches, the other wire shrinks by the same length, so the following relationship holds,

$$
\left(d_{p 1}+d_{h 1}\right)+\left(d_{p 2}+d_{h 2}\right)=\alpha_{1} f+\alpha_{2} f^{\prime}=0
$$

where

$$
\alpha_{i}=\left(n_{i} / K_{p i}+1 / K_{h i}\right), i=1,2
$$

Therefore, the damper force $Q$ is evaluated as
$Q(x, \dot{x})=f-f^{\prime}=\left(\frac{\alpha_{1}+\alpha_{1}}{\alpha_{2}}\right) f$

The force of the truss can be obtained from the force of the damper by the following equation.

$N_{1}=n_{1}\left(\frac{\alpha_{2}}{\alpha_{1}+\alpha_{2}}\right) Q, \quad N_{2}=-n_{2}\left(\frac{\alpha_{1}}{\alpha_{1}+\alpha_{2}}\right) Q$

The deformation of the damper is given by

$x=-n_{1} \delta_{1}+d_{p 1}+d_{h 1}=-n_{1} \delta_{1}+\alpha_{1} N_{1} / n_{1}$

Therefore, the procedure to implement into the frame analysis is:

Step 1 Using the force $N_{1}$ and displacement $\delta_{1}$ of the truss, find the deformation of the damper from Eq. (12).

Step 2 Determine the damper force $Q(x)$ from the load deformation relationship of the damper.

Step 3 Update the truss axial forces $N_{1}, N_{2}$ from Eq. (11)

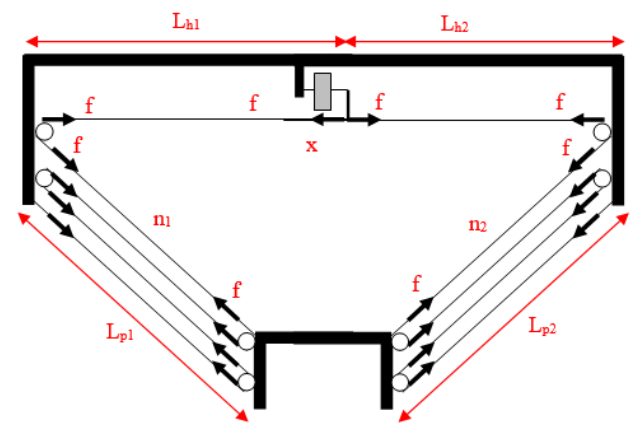

Figure 7. Both sides of the pulley damper system

The dynamic pulley damper is implemented in the computer program, STERA_3D [6], developed by one of the authors for three-dimensional earthquake response analysis of buildings.

\section{SMALL SCALE SHAKING TABLE TEST}

\subsection{Outline of the Test Specimen}

The outline of the test specimen for the shaking table test is shown in Figure 8. The specimen consists of two parts; a four-story frame part and a core part in the centre. The floor of the specimen is made of steel plates and the column is made of ultra-duralumin plates. A steel plate with $150 \mathrm{~mm}$ length and $2 \mathrm{~mm}$ thickness is used as a hysteresis damper. The damper is placed at the ceiling of the 3 rd floor, and wires are connected at the end. The yield strength of the damper is about $14 \mathrm{~N}$. The initial tension of the wire is 
$30 \mathrm{~N}$. The left side of Figure 8 represents the stationary state, and the right side represents the deformed state. The view of the specimen is shown in Figure 9.

\subsection{Input Waves and Test Cases}

The conditions of the experiment are shown in Table 1. A model in which the frame part and the core part are not connected is [Case F]. A model in which the frame part and the core part are connected by wire and pulleys is [Case FW]. And a model in which a steel damper is introduced is [Case FWD]. In Case FWD model, the thickness of the core plate is changed as 12 $\mathrm{mm}$ (hard model) and $7 \mathrm{~mm}$ (soft model).

Table 1. Test cases

\begin{tabular}{|l|c|c|c|}
\hline & Case $\mathrm{F}$ & Case FW & Case FWD \\
\hline Tension of wire $(\mathrm{N})$ & & 30 & 30 \\
\hline Size of steel damper $(\mathrm{mm})$ & & & $2 \times 6$ \\
\hline Size of core plate $(\mathrm{mm})$ & & 12 (hard) & 12 (hard) \\
& & & 7 (soft) \\
\hline
\end{tabular}

As input waves, we used three waves of $1940 \mathrm{El}$ Centro wave, 1968 Hachinohe wave, and 1995 JMA Kobe wave, changing the original time scale $1 / \sqrt{10}$ times to consider scale effect. Figure 11 shows the input waves normalized to have the maximum velocity of $50 \mathrm{~cm} / \mathrm{s}$. Figure 10 shows the input waves.

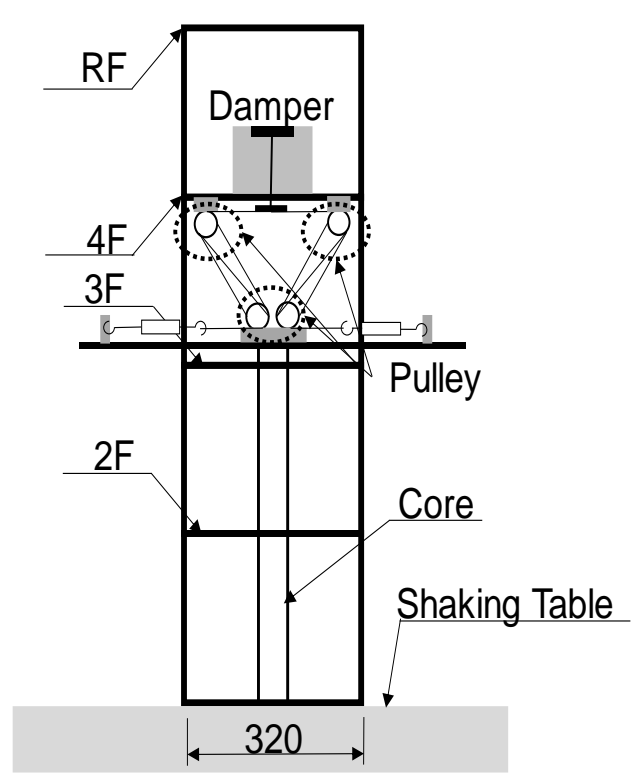

\subsection{Test Results}

Figures 11 to 13 show the relationships between the maximum input acceleration and the maximum displacement at each floor of the specimen under El Centro, Hachinohe and JMA Kobe waves. The maximum displacement of each floor is obtained from the difference between the displacement of each floor of the specimen and the displacement of the shaking table.

In the case of El Centro wave in Figure 12, Case FW can suppress more building displacement than Case F.

There is no difference in damping effect between Case FW and Case FWD up to an acceleration of about $100 \mathrm{~cm} / \mathrm{s} 2$ in the $3 \mathrm{rd}$ and 4th floors, and up to an acceleration of $200 \mathrm{~cm} / \mathrm{s} 2$ in the 1st and 2nd floors. However, when the input acceleration is higher than $200 \mathrm{~cm} / \mathrm{s2}$, the damping effect of Case FWD is prominent.

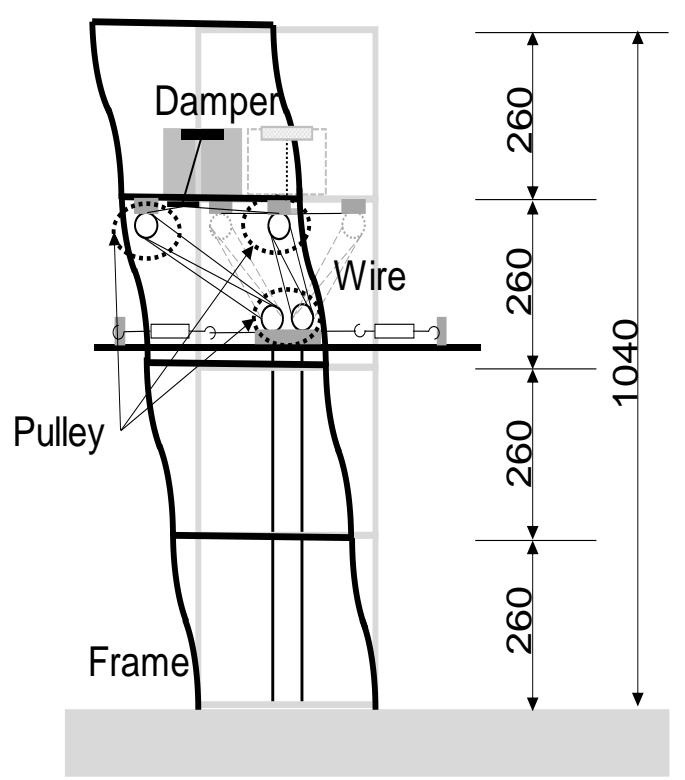

Figure 8. Outline of the test specimen of the shaking table (Unit: $\mathrm{mm}$ ) 


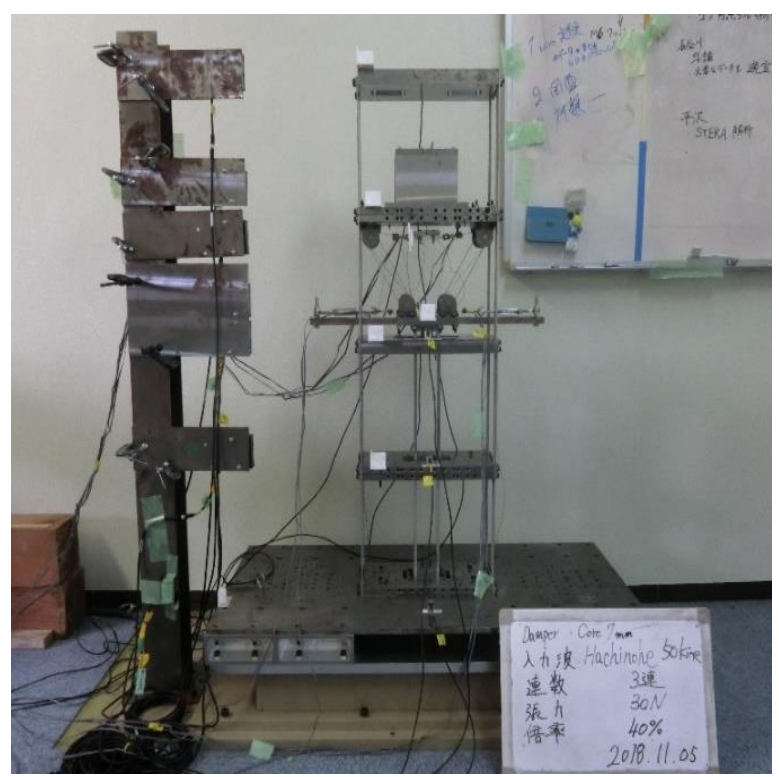

Figure 9. View of the test specimen

In the case of Hachinohe wave in Figure 13, Case F and Case FW have similar damping effect. In Case FWD which introduced a damper, the deformation is suppressed both in the soft model and the hard model of the core part.

In the case of JMA Kobe wave in Figure 14, the difference of the damping effect under each experimental condition did not appear in the 1st and the 2 nd floors.
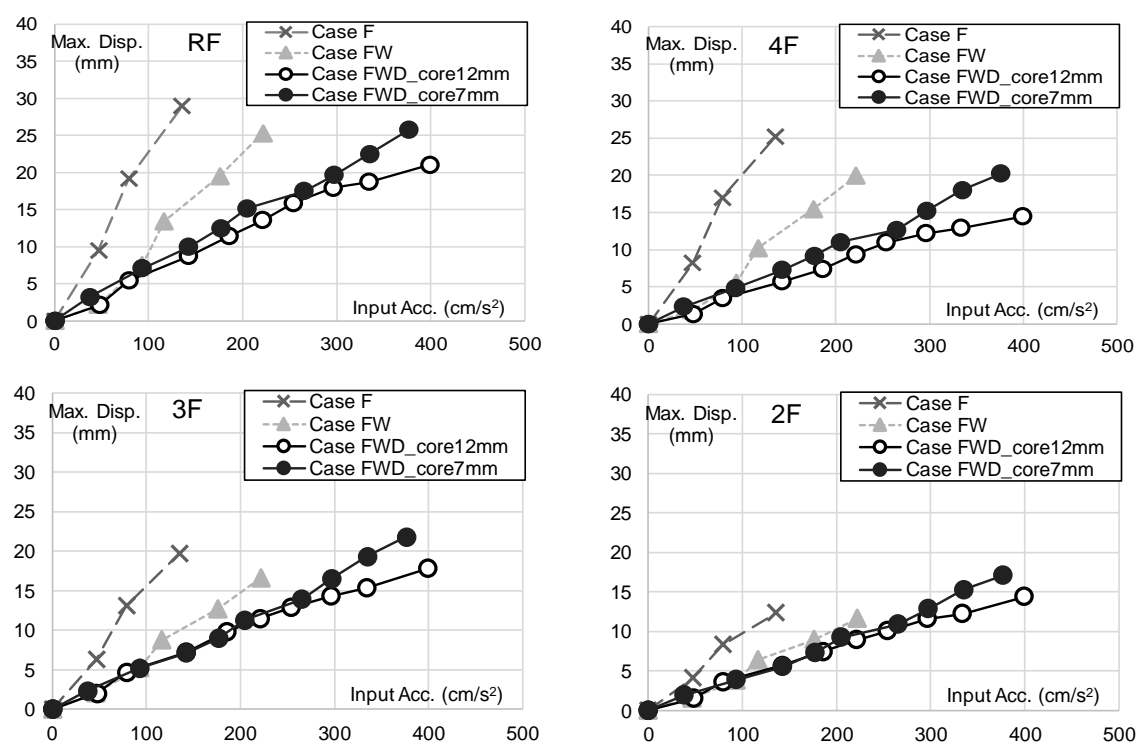

Figure 11. Maximum Floor Displacement under El Centro Wave 

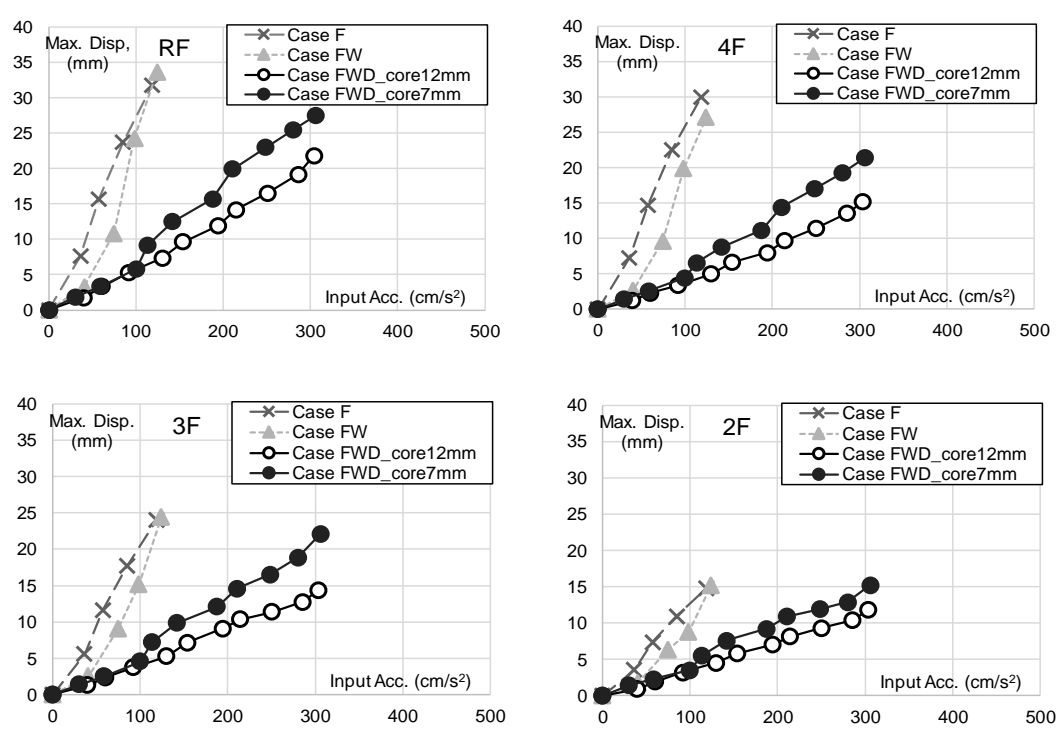

Figure 12. Maximum Floor Displacement under Hachinohe Wave
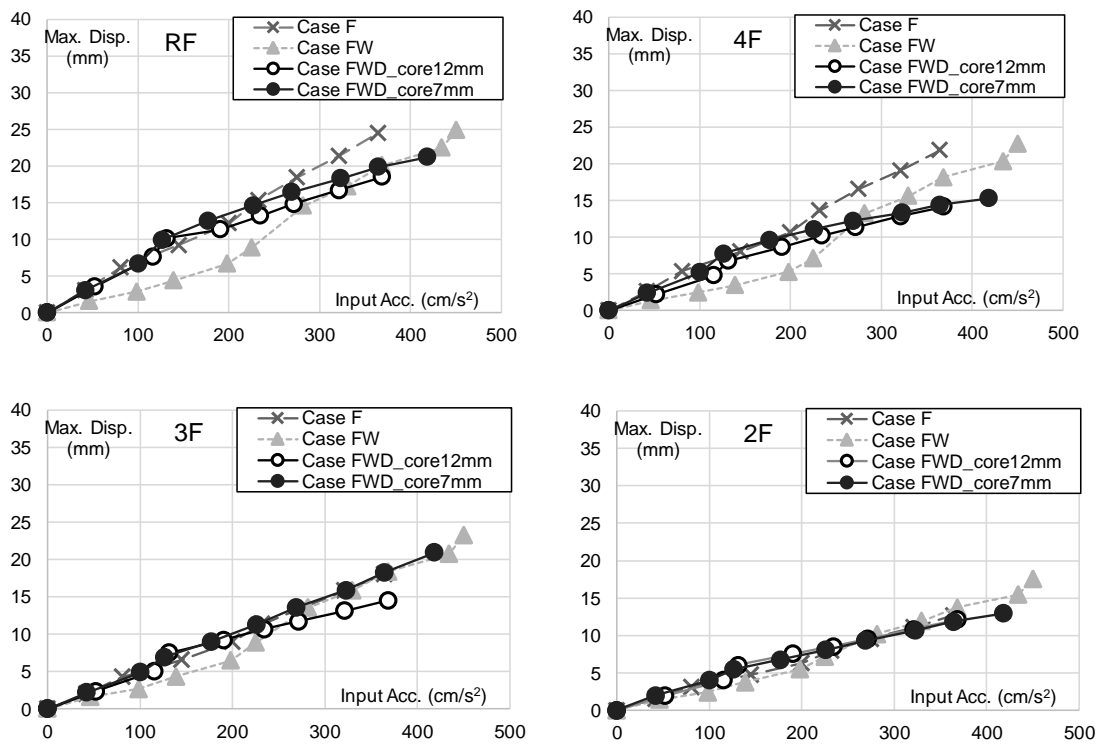

Figure 13. Maximum Floor Displacement undJMA Kobe Wave

\subsection{Simulation Analysis}

Figure 14 shows the STERA 3D model for the simulation of test results. Figures 15 and 16 show the comparison of the maximum displacement between analysis and test results under El Centro Wave for Case FW and Case FWD, respectively. In case of Case Figure 15, the analysis and test results correspond relatively well. On the other hand, in case of Case FWD figure 16 , the analysis results are generally smaller than the test results. It means that the model of the damper device must be improved for the future study.

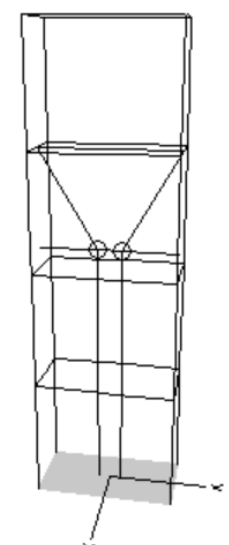

Figure 14. STERA_3D model 

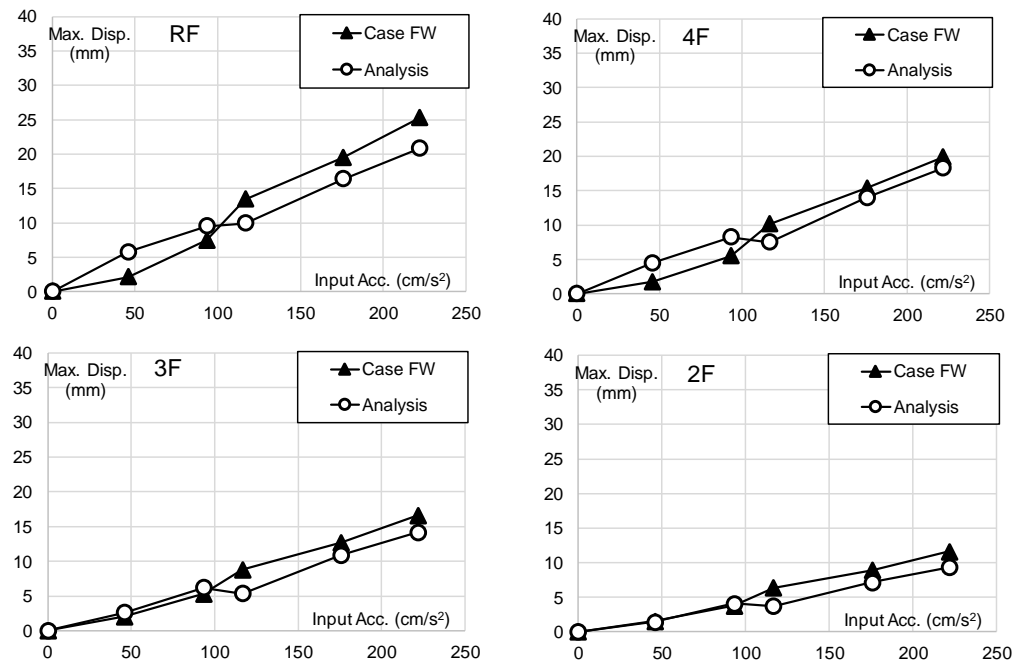

Figure 15. Comparison between Analysis and Test Results under El Centro Wave for Case FW
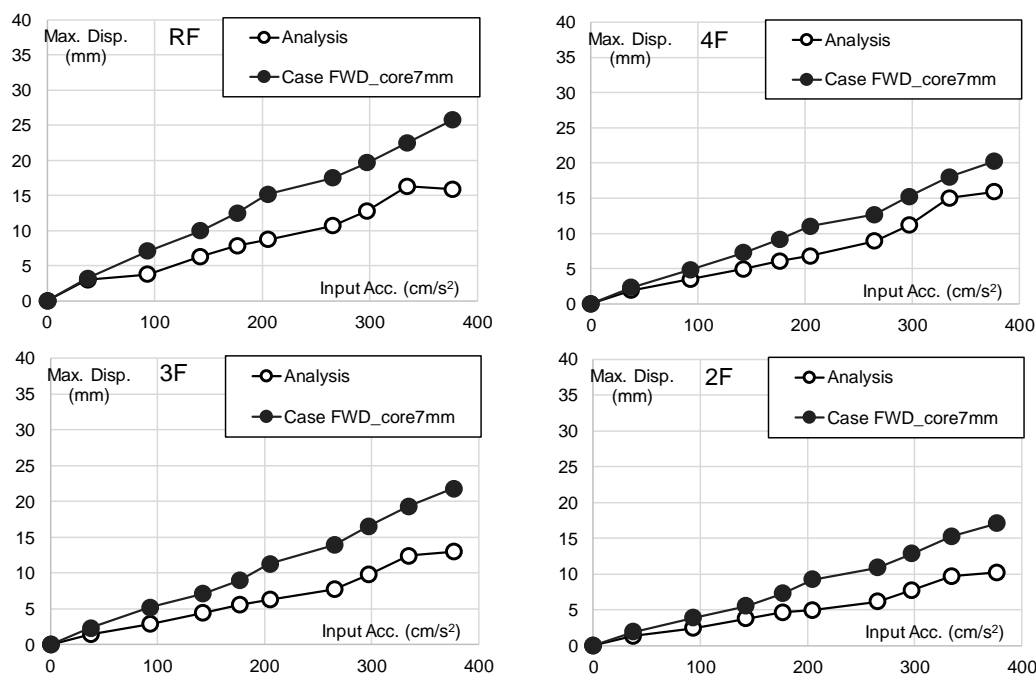

Figure 16. Comparison between Analysis and Test Results under El Centro Wave for Case FWD

\section{LARGE SCALE SHAKING TABLE TEST}

\subsection{Outline of the Test Specimen}

The sectional view of the specimen is shown in Figure 17, and the full view photo is shown in the Figure 18. The specimen consists of a steel frame corresponding to the surrounding frame and a core part corresponding to the core structure, and a dynamic pulley damping system is attached between the steel frame and the core part. To set the natural period of the outer frame about 1 second, the weight was increased by loading a weight and the frame is supported by laminated rubber bearings. The weight of the specimen of the outer frame is $180 \mathrm{kN}$, and the natural period at the time of design is $1.25 \mathrm{sec}$.
The dynamic pulley system is equipped with a pulley device capable of supporting from 0 to 6 grooves of pulley and the wire rope is constructed with filler type $6 \times \mathrm{Fi}$ (29) with a diameter of $12 \mathrm{~mm}$, the tension of the wire is $10 \mathrm{kN}$ (about 10\% of the breaking load).

Acceleration and displacement of the specimen are measured with an accelerometer and a laser type displacement gauge attached to the outer surrounding frame portion, and the displacement of the center portion of the wire rope was measured with a wire displacement meter. The tension of the wire was measured by load cells installed at the pulley mounting portion at both ends of the wire and at the center of the wire. 
The test series were conducted with the magnetic damper produced by Sanwa Tekki Corporation. The magnetic damper has a linear characteristic with a damping coefficient of $300 \mathrm{Ns} / \mathrm{m}$ for 6 units $(50 \mathrm{Ns} / \mathrm{m}$ for each unit) and the maximum stroke displacement is $\pm 200 \mathrm{~mm}$. Figure 19 shows the view of the damper and Figure 20 shows the force deformation characteristics of the damper for one unit under $1 \mathrm{~Hz}$ excitation. Table 2 shows the characteristics of wire and Table 3 shows the specification of magnetic damper.
Table 2. Characteristics of wire

\begin{tabular}{|l|l|}
\hline & Wire $(\varphi$ 12) \\
\hline Young Coefficient & $100,000(\mathrm{~N} / \mathrm{mm} 2)$ \\
\hline Section area & $56.6(\mathrm{~mm} 2)$ \\
\hline
\end{tabular}

Table 3. Specification of magnetic damper

\begin{tabular}{|c|c|}
\hline Stroke & Damping coefficient \\
\hline $\pm 400 \mathrm{~mm}$ & $300 \mathrm{Ns} / \mathrm{m}$ \\
& 1 unit $(50 \mathrm{Ns} / \mathrm{m})$ \\
\hline
\end{tabular}

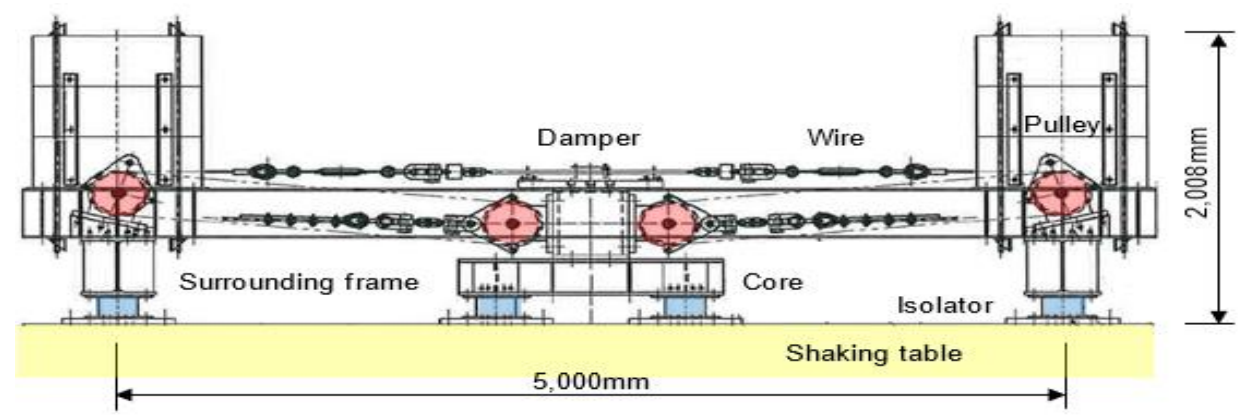

Figure 17. The sectional view of the specimen

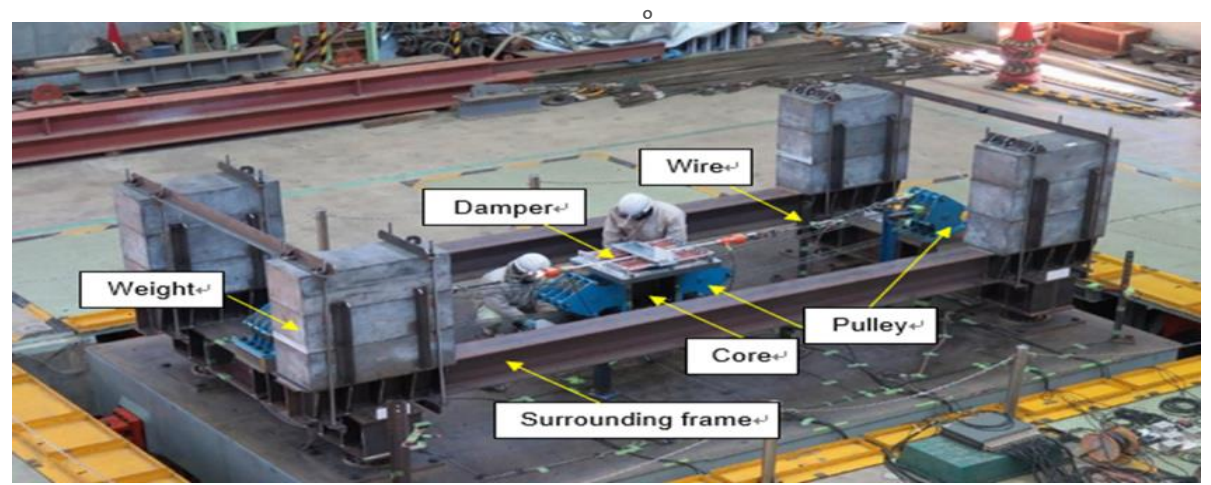

Figure 18. Full view of the specimen

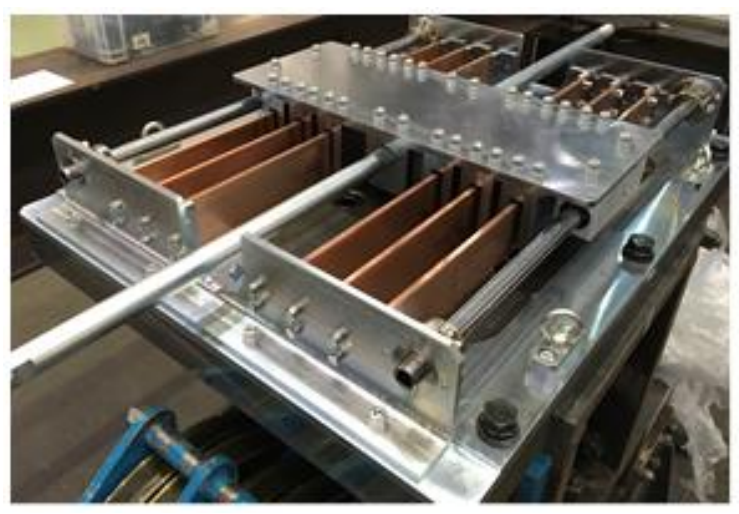

Figure 19. Magnetic damper

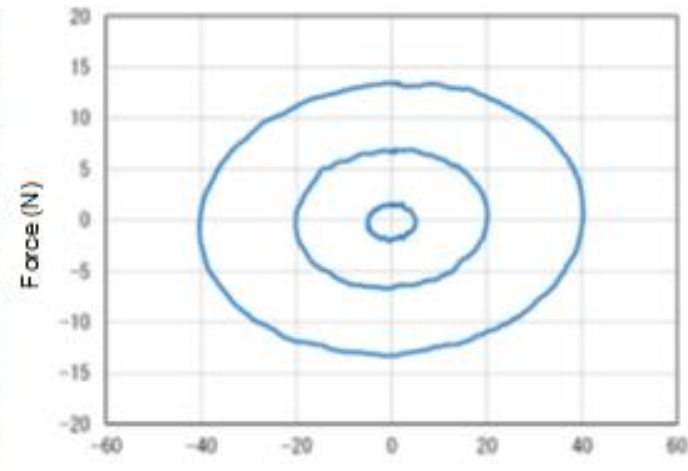

Figure 20. Force-deformation characteristics $(1 \mathrm{~Hz})$ 


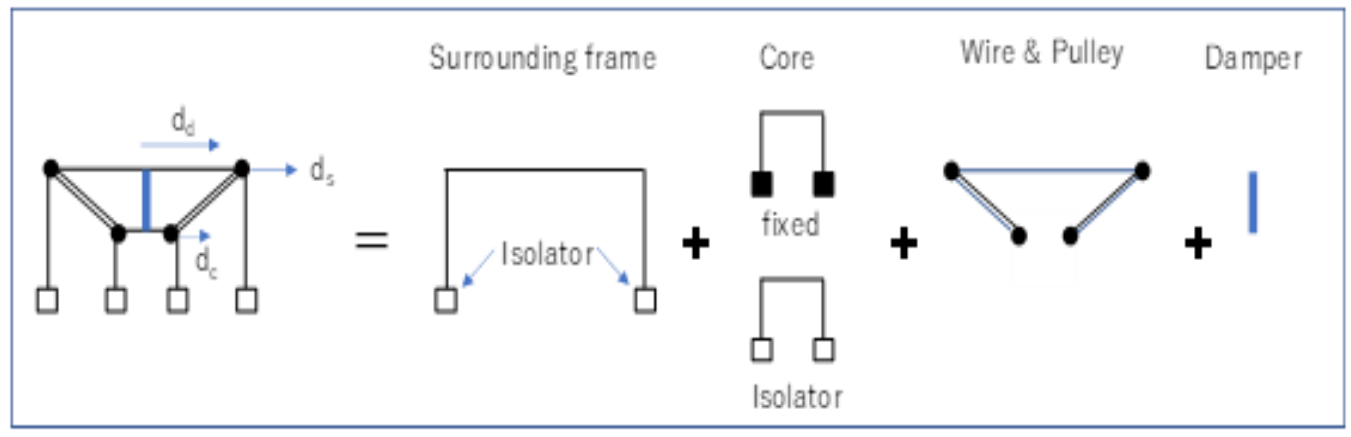

Figure 21. Schematic diagram of analysis case
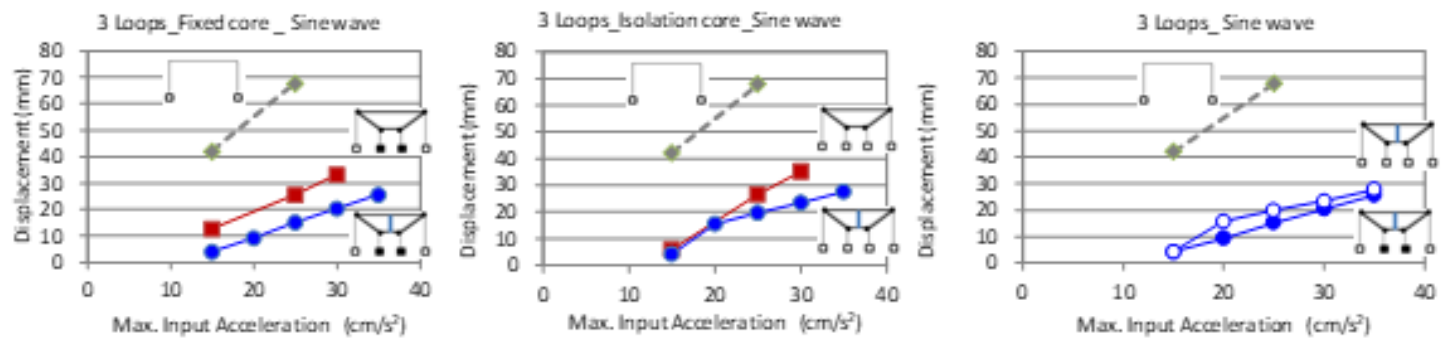

(a) Sine wave excitation
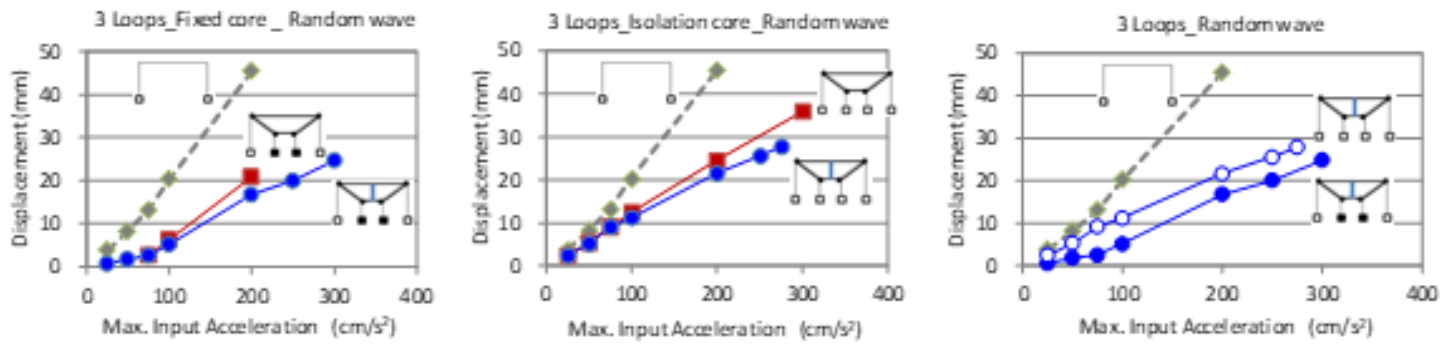

(b) Random wave excitation

Figure 22. Maximum displacement of the surrounding frame $d_{s}$ for the loop number three

\subsection{Test Cases and Excitation Conditions}

In the test, there are three cases of the number of wire loops around the pulleys: 1, 3, and 5, and two cases of base condition of the core structure: fixed base and non-fixed base sup-ported by laminated rubber bearings. The natural frequency of the surrounding frame is confirmed to be $0.98 \mathrm{~Hz}$ from the test without the wire and the damper.

The element test is a vibration test in one direction ( $X$ direction). Two types of excitation were carried out: random wave (with 0.5 to $30 \mathrm{~Hz}$ flat spectrum and 80 sec duration) and SINE wave excitation with the frequency of $0.98 \mathrm{~Hz}$. Each vibration test was carried out by in-creasing gradually the level of excitation.
The first test series were conducted without the damper device to examine the friction between wire and pulley. The second test series were conducted with the magnetic damper.

\subsection{Test Results}

To make it easier to understand the analysis case, we use the schematic diagram as shown in Figure 21, where $d_{s}$ is the maximum displacement of the surrounding frame, $d_{c}$ is that of the core, and $d_{d}$ is the displacement of the damper.

Figure 22 shows the maximum displacement responses of the surrounding frame for sine wave excitation and random wave excitation for loop number three. It is seen that the response of the surrounding frame can be reduced by simply setting a 
wire (red line). Adding a damper further reduces the response (blue line). Response reduction is greater when the core is fixed.

\subsection{Simulation Analysis}

Figure 23 shows the STERA 3D model for the test specimen. Together with the damping force of the magnetic damper, the friction between wire and pulley is considered as a bilinear hysteresis damper.

The friction force is assumed to be $0.3 \mathrm{kN}$ determined from the static loading test of wire and pulley.

The displacement responses are compared between analysis and test results in Figure 24 to Figure 27. Both results are in good agreement.

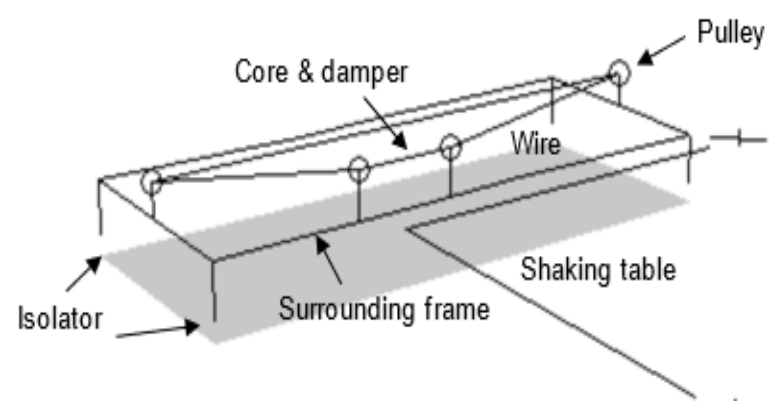

Figure 23. STERA_3D model of the test specimen
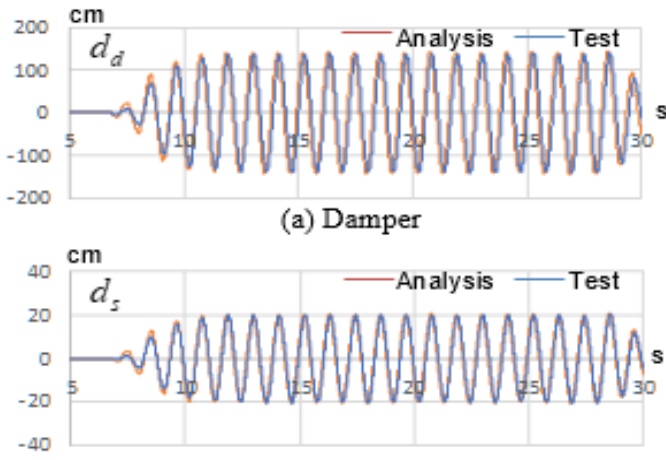

(b) Surronding frame

Figure 24. Displacement response under SINE excitation of 30 gal (fixed core \& loop number 3 )

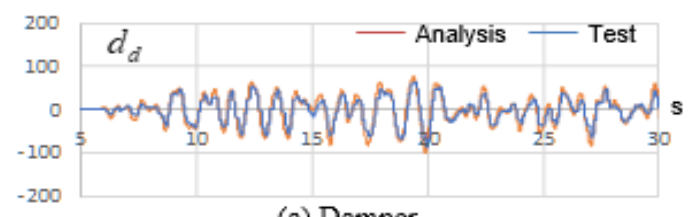

(a) Damper

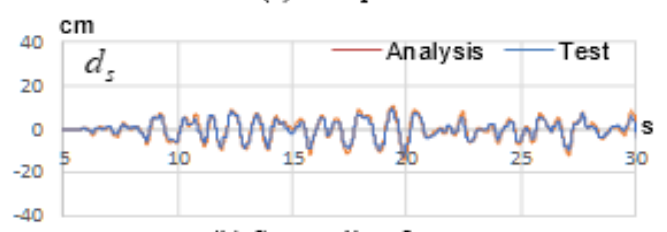

(b) Surronding frame

Figure 25. Displacement response under random excitation

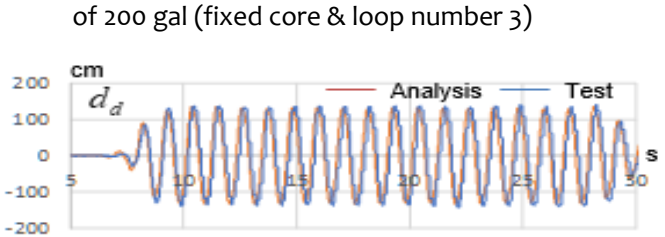

(a) Damper

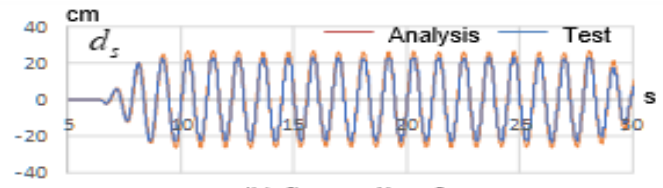

(b) Surronding frame

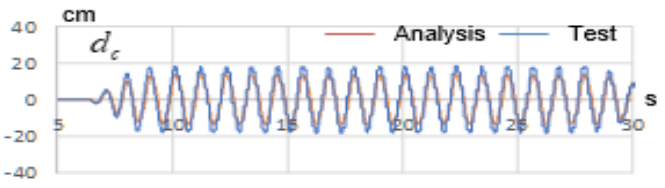

(c) Core

Figure 26. Displacement response under SINE excitation of 30 gal (isolation core \& loop number 3 )

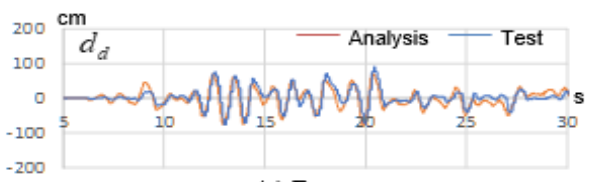

(a) Damper

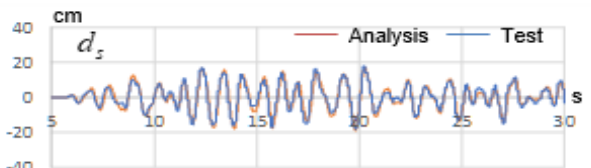

(b) Surronding frame

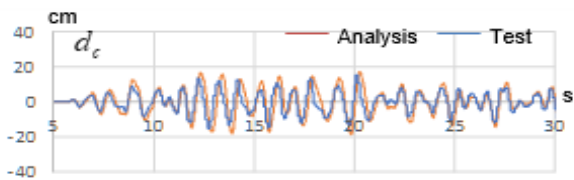

(c) Core

Figure 27. Displacement response under random excitation of $200 \mathrm{gal}$ (isolation core \& loop number 3 )

\section{CONCLUSIONS}

This paper proposed a new seismic response control system using a block and tackle, named as a dynamic pulley damper system. Two types of shaking table tests were conducted for the specimens simulating the core structure and the peripheral frame of a high-rise building. It was verified that the new system effectively reduced the building response. Also the analysis models using the constitutive formula developed in this study simulated the test results successfully.

\section{REFERENCES}

[1] H Kurino H, et al. 2017 Development of Large Tuned Mass Damper with Stroke Control System for Seismic Upgrading of 
Existing High-rise Building, 16th World Conference on Earthquake Engineering, Santiago Chile

[2] Saito T, et al. 2013 Proposal and Application of Seismic Contro Structure using Block and Tackle System, Journal of Structural Engineering, 59 (B), (in Japanese)

[3] Saito T, et al. 2017 New Seismic Response Control System using Block and Tackle, 16th World Conference on Earthquake Engineering, Santiago Chile

[4] Denno S, et al. 2014 Seismic Control Structure using Block and Tackle System - Vibration Tests of Building Amplification
Mechanism Damper Installation Parietal-, Journal of Structural Engineering, 60(B), Japanese

[5] Saito T, et al. 2019 Seismic Control Structure using Block and Tackle System - Element vibration experiment considering of an application to coupled vibration control system with a damper -, Journal of Structural Engineering, 65(B), Japanese

[6] Saito T STERA_3D, http://www.rc.ace.tut.ac.jp/saito/softwaree.html 